\title{
January 2020 Mexican Journal of Neuroscience
}

\author{
Ildefonso Rodríguez-Leyva* \\ Neurology Service, Hospital Central "Dr. Ignacio Morones Prieto," Universidad Autónoma de San Luis Potosí, San Luis Potosí, Mexico
}

We begin a new year, and as each cycle that begins, new purposes, ideas, goals, dreams, come to our mind, and the desire to make them come true seems firm, and we intend to fulfill them.

Our country, like the whole world, seems to be still looking for the best solutions in politics and the diversity of visions of the left, right, of communist, socialist, capitalist tendencies are among each other if dictatorship or democracy is the collective behavior that must be followed. The answer seems to continue to be sought by societies in different latitudes, and concordance is not yet established.

In health policies, the most effective, fair, and incorruptible model that serves the majority and that offers the best programs for prevention and treatment of the disease is also sought, through a system of education, vaccination, and proper ranking of health levels for each condition we face.

Medical science, however, is not democratic; it is not of economic convenience, although unfortunately, until now, it is more easily accessible to those who have more possibilities, at least in our homeland. Medical science seeks the truth, and for those who try to practice it, it is always challenging to find answers to the questions that appear daily in our professional practice.

In this issue, we try to answer questions in original investigations that give solutions, which, although they seem logical, provide us with certainty in the daily activities in neurology.
What are the differences in the risk factors, presentation, evolution, and outcome in the cancer patients concerning those who do not present stroke? In a study conducted at the National Cancer Institute of Mexico, these questions are answered.

In a second investigation, another fundamental question is answered. Is there a relationship between drug resistance in epilepsy and the presence of structural abnormalities seen in the magnetic resonance image? A study conducted at the Central Hospital of San Luis Potosí concludes on the need we have in Mexico to improve the infrastructure to perform early epilepsy surgery.

A third original work, carried out in the pediatric population and carried out at the Pediatric Hospital of Legaria in Mexico City, corroborates the desirability of managing with human immunoglobulin $\mathrm{G}$ since not having it increases the severity and complications at discharge four-fold.

The vascular neurology group of the University Hospital of Nuevo León, Mexico, presents a case of cardiogenic thromboembolism managed with apixaban, reviewing the literature of an infrequent problem $(<1 \%)$ but that we could face in our neurological practice and that could be applied to other situations of stroke.

Finally, a review paper is presented in this issue that all of us who are involved in neurosciences are passionate about; what is the variation of brain neurotransmitters in circadian rhythms? What are the external factors besides the light and dark that favor modification in

\section{Correspondence:}

*Ildefonso Rodríguez Leyva

Department of Neurology, Hospital Central

"Dr. Ignacio Morones Prieto," Universidad Autónoma

de San Luis Potosí, San Luis Potosí, Mexico

Date of reception: 07-01-2020

Date of acceptance: 10-01-2020

E-mail: ilrole@yahoo.com.mx

DOI: 10.24875/RMN.M20000073
Available online: 03-02-2020

Rev Mex Neuroci. 2020;21(1):1-2

www.revmexneurociencia.com

1665-5044/@ 2020 Academia Mexicana de Neurología A.C. Published by Permanyer. This is an open access article under the CC BY-NC-ND license (http://creativecommons.org/licenses/by-nc-nd/4.0/). 
neurotransmitters levels? As these variations modify not only our behavior but also our ability to respond to environmental aggressors and our systemic functionality.

Although these contributions will surely have a modest impact on the health policies of our countries, the gift that each one of the authors shares with what they learn in their daily work will allow to make a difference, even if they seem to be only a drop of water that falls into the sea.
On behalf of all of those who work in this publication, I wish a new year full of strength, success, and happiness for each one of our readers. Moreover, we share the hope that everywhere in the world and in our country there exists the sincere wish of improving our education, our justice, and our health.

Finally, we would like to extend a special thank you to our reviewers and associate editors for their invaluable contribution to the journal. 